\title{
Danza, protesta y desidentificación: Una teoría político coreográfica del 2001
}

\author{
Dance, Protest, and Disidentification: A Political-Choreographic Theory of 2001
}

Dança, protestos e desidentificação: Uma teoria político coreográfica de 2001

(iD) Juan Ignacio Vallejos

juanigvallejos@gmail.com

CONICET, Instituto de Artes del Espectáculo, Universidad de Buenos Aires, Argentina

Recepción: 04 Mayo 2021

Aprobación: 22 Mayo 2021

Publicación: 01 Diciembre 2021

Cita sugerida: Vallejos, J . I. ( 2021) . Danza, protesta y desidentificación: Una teoría político coreográfica del 2001. Aletheia, 12(23), e105. https://doi.org/10.24215/18533701e105
Resumen: El objetivo de este artículo será el de proponer un análisis de las obras de danza contemporánea argentina Recorte de Jorge Cárdenas Cayendo (2017) creada por la Compañía Terceto bajo la dirección de Juan Pablo Gómez e Instrumento para estrellar (2018) de la coreógrafa Diana Szeinblum, en diálogo con conceptos de teoría política y teoría de la danza. Las obras citadas retoman imágenes y secuencias de movimiento de la movilización de diciembre de 2001 y de otros levantamientos populares de Latinoamérica, para proponer diferentes modos de teorización coreográfica del acontecimiento político. Si como afirma Rancière, la subjetivación política supone una instancia previa de desidentificación, la tesis que propone este texto es que esa instancia se corresponde con la intervención de un cuerpo en movimiento. El estallido social puede ser entendido, de ese modo, como una experiencia coreográfica colectiva de desidentificación capaz de habilitar la emergencia histórica de un nuevo sujeto político.

Palabras clave: Danza contemporánea argentina, Danza y política, Arte y política, Crisis del 2001, Performance y política.

Abstract: This article will analyze the Argentine contemporary dance works Recorte de Jorge Cárdenas Cayendo (2017), created by Compañía Terceto and directed by Juan Pablo Gómez, and Instrumento para estrellar (2018), by choreographer Diana Szeinblum, in a dialogue with concepts of political theory and dance theory. These works take images and movement sequences from the December 2001 demonstrations and other Latin American popular uprisings to propose different modes of choreographic theorization of the political event. If, as Rancière states, political subjectivation presupposes a prior instance of disidentification, the thesis proposed in this article is that this instance corresponds to the agency of a body in movement. The social uprising can thus be understood as a collective choreographic experience of disidentification that is capable of enabling the historical emergence of a new political subject.

Keywords: Argentine contemporary dance, Dance and politics, Art and politics, Crisis of 2001, Performance and politics. 


\begin{abstract}
Resumo: O objetivo desse artigo é propor uma análise das peças de dança contemporânea argentina "Recorte de Jorge Cárdenas Cayendo" (2017), criada pela Companhia Terceto e dirigida por Juan Pablo Gómez e "Instrumento para estrellar" (2018) da coreógrafa Diana Szeinblum, em diálogo com conceitos da teoria política e teoria da dança. As peças citadas retomam imagens e sequências de movimento da mobilização de dezembro de 2001 e de outros levantamentos populares da América Latina, propondo diferentes modos de teorização coreográfica do acontecimento político. Se como afirma Rancière a subjetivação política supõe uma instância prévia de desidentificação, a tese que propõe esse texto é que essa instância corresponde à intervenção de um corpo em movimento. Desse modo, a explosão social pode ser entendida como uma experiência coreográfica coletiva de desidentificação que possa habilitar a emergência histórica de um novo sujeito político.
\end{abstract}

Palavras-chave: Dança contemporânea argentina, Dança e política, Arte e política, Crise de 2001, Performance e política.

\section{INTRODUCCIÓN}

A mediados del 2020, la compañía Terceto se propuso hacer un cortometraje documental que retomara la temática de su obra Recorte de Jorge Cárdenas cayendo. Se trataba de analizar el proceso compositivo y la temática abordada a partir del diálogo con artistas e investigadores. En ese marco, los integrantes de la compañía me convocaron para que diera mi testimonio junto a los fotógrafos Gonzalo Martínez y Julio Menajovsky, y a la investigadora Cora Gamarnik. Nos habíamos conocido hacía algunos meses porque había invitado a la compañía a participar de un ciclo de charlas sobre la crisis del 2001 y las artes escénicas, organizado por el Grupo de Estudios sobre Teatro contemporáneo, política y sociedad en América Latina del Instituto Gino Germani de la Facultad de Ciencias Sociales de la UBA. En todo caso, algo que me interpeló decididamente de la convocatoria fueron las preguntas que los integrantes de la compañía me enviaron para guiar mi participación en el documental. Las primeras dos eran: “¿Cómo fue tu vivencia de la crisis de 2001 en general, y del 19 y 20 de diciembre de 2001 en particular? ¿Cómo fueron esos días para vos?”.

Los científicos sociales no solemos comenzar un trabajo de investigación planteándonos cuál fue nuestra vivencia personal del acontecimiento que queremos estudiar. El proceso investigativo es entendido hasta cierto punto como la posibilidad de construir una distancia con respecto a nuestras impresiones personales. Sin embargo, lo primero que entendí al leer esas preguntas fue que, a diferencia de la experiencia de la última dictadura, la crisis del 2001 era un acontecimiento del que podía dar testimonio, del que había sido testigo presencial y del que incluso había participado activamente. Nací en 1976 y pertenezco, a grandes rasgos, a la generación de los HIJOS - hijos e hijas de militantes y de víctimas de la última dictadura que reivindicaron el legado político de sus padres y madres. Para nosotros, a diferencia de las generaciones posteriores - al menos, eso creo -, la memoria sobre la dictadura constituyó un elemento central para la conformación de nuestra subjetividad y, en particular, de nuestra identidad política. De hecho, los dos primeros artículos que publiqué en mi vida académica profesional estuvieron relacionados con ese tema. Pienso que no podría haber sido de otra manera. La dictadura se presentó a mi generación como una suerte de obsesión, una historia cercana y lejana al mismo tiempo, algo que nos conectaba con el pasado de una lucha que no habíamos protagonizado, pero que permanecía presente de una manera acechante. En el caso del estallido social del 19 y 20 de diciembre de 2001 el esquema era totalmente distinto. 
En principio, debo aclarar que para mí ese estallido social no fue el comienzo de una crisis, sino su finalización. Recuerdo muy claramente el dibujo de Rep en la contratapa del diario Página 12 en esos días. Era una lápida que decía “Miedo, nació el 24 de marzo de 1976, murió el 19-20 de diciembre de 2001". Coincidí totalmente con esa interpretación, en ese momento. El miedo al terrorismo de Estado se había transformado en los años noventa en miedo a la economía (neoliberal). Se la presentaba como una ciencia oculta reservada a unos pocos gurúes, detentores de un conocimiento mágico que debía ser acatado de modo riguroso. Recuerdo la angustia con la que se vivían las reiteradas visitas de los representantes del FMI y las columnas de los analistas económicos de los medios de comunicación hegemónicos. A la legitimidad inapelable del discurso neoliberal se le sumaba una atención acongojada al comportamiento de los mercados y a la "solvencia" económica del Estado. El quiebre de la legitimidad política y discursiva del neoliberalismo, que se presentaba detrás de la máscara de una facticidad económica indiscutible, se dio en Argentina gracias al levantamiento popular del 2001. Coincido con Diego Sztulwark (2019) en que el 2001 representó un "legado político" del pueblo que fue asumido por el kirchnerismo, aunque no creo, como él afirma, que haya sido "traicionado" por esa fuerza política.

Mi lectura sobre ese momento histórico es uno de los elementos que permean mi interpretación del estallido del 19 y 20 de diciembre del 2001, sin embargo, otro elemento que la define es la memoria de una experiencia física, ya que yo mismo participé de esa manifestación. En ese entonces, vivía junto a mi hermano en el barrio de Congreso de la ciudad de Buenos Aires, que fue uno de los epicentros del levantamiento. Fuimos junto a él y a mi padre a la Plaza del Congreso y luego marchamos hasta la Plaza de Mayo en la noche del 19. Allí fuimos reprimidos por la policía federal con gases lacrimógenos. El olor de los gases se llegaba a sentir en el living de mi casa. Retrospectivamente, no recuerdo haber sentido miedo en ningún momento. Por el contrario, sentí una suerte de liberación, el desbloqueo de algo que me estaba resultando intolerable. La complicidad afectiva de quienes estábamos ahí, nos imbuía de una sensación de certeza con respecto a lo que estábamos haciendo. Fue lo más cercano a un sentimiento de solidaridad que experimenté en toda mi vida.

La sociedad de los noventa en Argentina estaba claramente polarizada, hubo sectores que se enriquecieron mucho y otros que vivieron al borde de la indigencia. Personalmente, fui parte de la mitad de la sociedad que sufrió en carne propia el neoliberalismo: los salarios de miseria, el terror al desempleo, la total desazón con respecto al futuro. Releo estas palabras y percibo que quien escribe es en parte mi yo veinteañero, aún angustiado. Quizás sea ese el lugar de enunciación de este texto a pesar de toda la prudencia epistemológica que pueda anteponer. El estallido constituyó, desde mi punto de vista, un quiebre en el terreno de lo sensible, a partir del cual, la vivencia de la opresión del sistema neoliberal se volvió intolerable. El concepto de lo intolerable utilizado por el antropólogo Didier Fassin (Fassin y Bourdelais, 2005) señala el momento en el que un fenómeno resulta imposible de asimilar para una sociedad determinada. Es un punto en el que el rechazo se percibe de un modo corporal y afectivo, aunque funcione, a su vez, como la base de una expresión discursiva.

El objetivo de este artículo será el de proponer un análisis de las obras de danza Recorte de Jorge Cárdenas Cayendo (2017), creada por la Compañía Terceto bajo la dirección de Juan Pablo Gómez, e Instrumento para estrellar (2018) de la coreógrafa Diana Szeinblum. Se trata de obras que retoman imágenes y secuencias de movimiento de la represión de diciembre de 2001 y de otros levantamientos populares de Latinoamérica para proponer diferentes modos de teorización coreográfica del acontecimiento político. Si aceptamos, como sostiene Randy Martin (1998) que las obras de danza producen teorizaciones cinético-afectivas del orden social, podemos proponer que hay un saber específico en la movilización política del 19 y 20 de diciembre de 2001 que deviene comprensible sólo a través de la reflexividad del cuerpo danzante. En este mismo sentido, si como afirma Rancière (1996), la subjetivación política, entendida como la emergencia de la "parte de los sin parte", supone una instancia previa de desidentificación, la tesis que propone este texto es que esa instancia comprende la intervención de un cuerpo en movimiento. El estallido social del 2001 puede ser entendido, de ese modo, como una experiencia coreográfica colectiva de desidentificación coincidente con la emergencia histórica de un nuevo sujeto político. 


\section{LA CAÍdA de Jorge CÁrdenas}

La obra Recorte de Jorge Cárdenas cayendo se estrenó en noviembre de 2017 en el FICI (Festival Internacional de Circo Independiente) y continuó siendo presentada en diferentes versiones entre 2018 y 2019, hasta ser seleccionada para el FIBA (Festival Internacional de Buenos Aires) en 2020. Si bien en su primera versión incluía solamente música en vivo y coreografía, luego de una residencia artística en el "Laboratorio de Interactividad Corporal” del Centro Hipermediático Experimental Latinoamericano (CheLA) la obra comenzó a incluir, en colaboración con Pariguayo, la proyección de materiales audiovisuales ligados al estallido de diciembre del 2001.

El título de la obra hace referencia a una de las fotos testimoniales más famosas de la represión de aquella noche, la que retrata a Jorge Cárdenas caído inconsciente en las escalinatas del Congreso junto a un charco de sangre. Cárdenas era un martillero público del Partido de Merlo de la Provincia de Buenos Aires que había concurrido a la manifestación con su hijo y un vecino. En la madrugada del 20 recibió dos impactos de bala en las piernas y cayó inconsciente. Afortunadamente, logró ser asistido y no murió esa misma noche, pero lo hizo un tiempo después debido a complicaciones de salud que se agravaron con ese episodio. Como señala Juan Pablo Gómez ${ }^{1}$, director de la obra, resulta paradójico que Cárdenas, cuya foto es uno de los registros más impactantes y difundidos de aquella noche, no haya sido contabilizado como una víctima directa de la represión y, por ende, su familia no haya recibido ninguna indemnización luego de su muerte. El hecho de que uno de los símbolos de la violencia estatal en el 2001 no haya sido contabilizado como una víctima efectiva de la represión nos invita a pensar en las sujeciones silenciosas del neoliberalismo. O quizás en la idea misma de que el neoliberalismo es un sistema represivo silencioso que genera víctimas que no siempre son contabilizadas como tales.

En todo caso, la imagen de Jorge Cárdenas caído funcionó como un aglutinador de sentido, un punto de partida para el trabajo coreográfico. En la sinopsis que acompaña la presentación de la obra se lee:

La foto de Jorge Cárdenas, primer herido en la represión de diciembre de 2001, fue la primera imagen. Su cuerpo tirado sobre las escalinatas del Congreso de la Nación, el tono de sus músculos, sus miembros desorganizados y el rastro de sangre que sugieren su último recorrido, despertaron una serie de preguntas: ¿cómo contar una tragedia tan grande e íntima desde el propio cuerpo? ¿Puede el movimiento narrar la Historia? ¿Qué aspectos de esa Historia resuenan, todavía, en nuestros huesos?

En principio, la sinopsis hablaría de una propuesta dramatúrgica casi historiográfica. El propósito es el de explorar una narración histórica de lo sucedido desde el cuerpo, o presentar una reflexión acerca de las posibilidades narrativas del cuerpo en movimiento en relación con un acontecimiento histórico político trascendente. La obra englobaría, de este modo, reflexiones metodológicas diversas y establecería un puente con la experiencia histórica como eje articulador. Sin embargo, como afirma Florencia Montaldo ${ }^{2}$, la imagen de Cárdenas llegó después de varios ensayos. El comienzo del trabajo estuvo ligado a la posibilidad de tratar desde un lenguaje de movimiento proveniente del circo un tema histórico y político "serio". Los tres integrantes del Grupo Terceto se conocieron durante su formación en la licenciatura en Circo de la UNSAM, en donde integraron la compañía de Gerardo Hochman. Querían abordar un tema que los conmoviera y coincidieron en que el estallido de diciembre de 2001 era un punto de encuentro entre sus diferentes recorridos personales. Sin embargo, emergía a la vez una pregunta formal en el proyecto: ¿cuáles son los límites del lenguaje coreográfico del circo? ¿El circo tiene solamente la capacidad de entretener o generar asombro?

Las obras de circo suelen abordar una gama de temas predefinidos ligados al humor, a lo maravilloso, a la proeza física, a la destreza y al equilibrio del cuerpo. El género en sí constituye un lenguaje de movimiento muy codificado, como lo es la danza clásica. Existe una serie de gestos y acciones preestablecida que suele repetirse en mayor o menor medida. Como respuesta a esto, la propuesta inicial del grupo fue una deconstrucción del cuerpo acrobático, generalmente concebido como un cuerpo virtuoso, potente: un cuerpo que representa la 
elevación. La puerta de entrada a esa deconstrucción fue la idea de caída, la imagen de un cuerpo fragmentado que sigue la gravedad. La foto de Cárdenas devino el punto de encuentro entre una búsqueda formal tendiente a subvertir las limitaciones del lenguaje coreográfico del circo y la posibilidad de construir un relato político e historiográfico a partir del cuerpo en movimiento.

En el comienzo, el escenario muestra tres intérpretes, Florencia Montaldo, Patricio Testolín y Pablo Censi, entre luces y sombras, vestidos con ropa de calle, sobre un fondo negro. Al costado, una tela sobre la que se proyectan imágenes audiovisuales. Los sonidos en escena reproducen ruidos de la calle, mezclados con ritmos electrónicos y arpegios ejecutados por sintetizadores. Los cuerpos son fuertes y atléticos, con un nivel de tonicidad más alto que el de un bailarín o una bailarina de danza contemporánea. Entre las sombras, se vislumbra un carrito de supermercado. El objeto remite a los saqueos, que fueron uno de los actos de resistencia frente a la crisis económica. Luego de una introducción con gestos sutiles y poses mesuradas, comienzan a sucederse escenas vertiginosas. Los cuerpos de Florencia y Patricio se arrojan a los brazos de Pablo que los recibe con reticencia. Sobrevuela una sensación de conflicto o de lucha, similar a la que puede vivirse en una manifestación en la vía pública. Cuerpos que se empujan, se desplazan, arremeten unos a otros. Queda expresada una dinámica de fuerzas en pugna unida a la severidad de la represión, el forcejeo, la voluntad de detener el movimiento del otro. Luego Pablo comienza a esbozar gestos de dolor y se coloca en el centro de la escena con su cuerpo desarticulado, una acción que nos hace pensar en un Cárdenas de pie.

La urgencia y la violencia arremeten de diversas maneras, incluso a partir de la utilización de objetos como el carrito o las piedras. Así, las escenas de acrobacia intervienen en un contexto de representación del conflicto que hace que la tensión por la proeza no cumpla exclusivamente el objetivo formal de generar asombro, sino que representa una suerte de desacato. Las piruetas devienen formas de rebeldía. Es allí donde aparece la arriesgada escena de la torre, en la que Pablo se sube al carrito de supermercado y Florencia se sube a sus hombros haciendo equilibrio.

Es luego de esa utilización de la acrobacia circense como gesto político que se hace presente una representación de la caída. A parece el cuerpo de Pablo caído en el piso en un gesto que reproduce exactamente el de Cárdenas en la foto. El movimiento se detiene. Los intérpretes comienzan a manipular ese cuerpo caído, a intentar levantarlo y sostenerlo, pero indefectiblemente cae. Luego exploran el gesto desarticulado de la caída desde la verticalidad del cuerpo. Las escenas nos transportan a diferentes estados que fluctúan entre la rebeldía, la lucha, la desazón y la vulnerabilidad. Hacia el final los intérpretes reproducen el gesto de arrojar piedras contra un muro en donde se proyectan imágenes de la represión en el 2001 y del conflicto socioeconómico de la época. Se superponen retratos de tensión social con spots que simbolizan la sociedad de consumo y los íconos del capitalismo financiero. Sin embargo, más allá de esa suerte de catarsis el desenlace vuelve a ser la imagen de un cuerpo abatido.

Al presentar una coreografía que toma como insumo a la manifestación social, la obra propone implícitamente el proceso inverso: leer las manifestaciones sociales como prácticas coreográficas. Las movilizaciones son acciones performáticas particulares que siguen pautas de movimiento definidas y que se construyen a partir de dispositivos específicos, roles predeterminados, entrenamientos. Susan Leigh Foster (2016) explora esta temática en su artículo "Coreografías de la protesta”, allí sostiene que la manifestación no es ni un momento de irracionalidad alterada, ni un acto especulativo que utiliza el cuerpo como instrumento en la búsqueda de beneficios específicos. Se trata de la entrega a una acción física que imbuye a los actores de un "profundo sentido de agencia personal" (Foster, 2016, p. 95). Este sentido se da a partir de la organización de los movimientos, el entrenamiento del cuerpo y el ejercicio de una determinada forma de percepción que responde a coyunturas políticas específicas. La coreografía de la protesta supone una instancia de respuesta física reflexiva que acciona en articulación con proyectos políticos. Ella estudia concretamente tres casos de activismo pacífico (las sentadas de militantes negros en cafeterías segregadas en los sesenta, las ocupaciones de ACT-UP de fines de los ochenta y las protestas contra la cumbre de la Organización Mundial del Comercio 
en Washington en 1999) y subraya los saberes del cuerpo que se movilizaban en esas acciones de resistencia al poder. Las manifestaciones son construcciones coreográficas complejas que movilizan y generan saberes en donde el cuerpo emerge como territorio y agencia.

En un texto posterior, Foster (2011) propone que la coreografía, entendida en un sentido amplio como un estilo de movimiento capaz de habilitar una instancia reflexiva, comprende a su vez una kinestesia, es decir una manera de experimentar la fisicalidad y el movimiento de modo individual, y una dimensión empática, a partir de la cual el movimiento convoca a otros cuerpos hacia una determinada forma cinética y sensible. Son dimensiones que enriquecen el estudio de las coreografías de la protesta ya que claramente quienes participan de ese tipo de acciones poseen una consciencia reflexiva de sus actos, un saber ligado a la experiencia física y emotiva de esa participación, y su práctica está determinada por una vinculación empática con un otro. Las acciones que se trabajan en Recorte de Jorge Cárdenas cayendo dialogan con experiencias físicas que pertenecen a una cultura coreográfica de la manifestación política, una cultura en la que estamos inmersos y que dialoga con los cuerpos a espaldas de la consciencia. La obra se sedimenta en el espectador como una experiencia de la rebeldía y de la acción directa.

Sin embargo, creo que a la trilogía coreografía, kinestesia, empatía, debería agregarse el factor visual de la representación del cuerpo. La danza - ciertamente no toda, pero una gran parte - es un movimiento concebido para ser observado. El cuerpo en movimiento en el espacio público y en la escena, es también una imagen en movimiento, y como tal, convoca elementos ligados a la cultura de los símbolos, a la representación de la forma e incluso a su subversión figurativa, es decir, a esos instantes en que el arte desborda el marco del sentido discursivo (Franko, 2019a, p. 108). La danza en Occidente ha sido históricamente una afrenta desestabilizadora de la dominación a través del dispositivo de la representación, teorizado por autores como Louis Marin (2009), pero eso no significa que funcione en un campo ajeno a los símbolos. La escena de la "torre" en la que Pablo se sube a un carrito de supermercado y Florencia se sube a sus hombros, no sólo es una acción vertiginosa, también articula una referencia simbólica. En todas las manifestaciones en las que he participado, al menos en Buenos Aires, siempre aparece una persona que realiza una acción temeraria: subirse a un poste de luz, a una escultura, a un árbol. Un individuo que en el contexto de una manifestación encarna un acto riesgoso a través de una acción que por otro lado está formalmente prohibida. La atmósfera de la obra nos permite entender que esos no son simplemente actos de rebeldía inocuos, sino acciones simbólicas que manifiestan el potencial quiebre de los márgenes de la política institucional, ya que expresan algo así como: no nos detendremos frente a la autoridad que se nos impone. Estamos haciendo algo probibido y peligroso, pero lo consideramos justo.

\section{MovilizAR LO INTOLERABLE}

Aquí emerge un tema que marca una diferencia tajante entre el análisis de Foster en "Coreografías de la protesta" y la obra del Grupo Terceto. Foster analiza el componente coreográfico de manifestaciones políticas pacíficas, mientras que la obra reflexiona acerca de un estallido social que más allá de que tuvo un apoyo organizativo latente, no dejó de ser un acontecimiento inesperado y severamente reprimido que dejó un saldo de 38 muertos. El 2001 fue una respuesta imprevisible, al menos para una amplia parte de la sociedad de ese entonces. La obra no tematiza sólo las tácticas corporales de una resistencia colectiva, también aborda la percepción física de la irrupción del acontecimiento, un fenómeno que, a su vez, convoca a la acción directa. Podríamos decir que el cambio político se produce cuando el orden pierde su legitimidad, cuando deja de ser percibido como justo, cuando su reproducción se vuelve intolerable. Como señalamos anteriormente, para Fassin y Bourdelais (2005, p.8), lo intolerable hace referencia a una configuración moral específica que surge cuando la transgresión de un límite deviene imposible de asimilar. No obstante, también designa en primera medida, un campo de lucha en el que se enfrentan diversas formas sensibles. Las variaciones en esa dinámica colectiva van marcando los cambios en las pautas hegemónicas del comportamiento moral. 
Por otra parte, lo intolerable es una experiencia que se ancla en el cuerpo, entendido como un fenómeno físico y político. Es físico porque remite a una materialidad concreta y a la experiencia de sensaciones específicas, pero es a la vez político porque involucra la dignidad y la concepción misma de la vida humana como un valor a ser defendido (Fassin y Bourdelais, 2005, p.9). La forma en que concebimos el cuerpo está socialmente determinada, pero es a su vez el vehículo de una experiencia individual. En este sentido, lo intolerable se encuadra en la esfera de la percepción, entendida como un componente ideológico determinante. La evolución histórica de las sensibilidades corre el límite de lo intolerable, prescribiendo nuevas prácticas sensibles. De este modo, deviene imposible ser indiferente a ciertos fenómenos una vez que son considerados intolerables. Podríamos decir que el estallido del 2001, se originó principalmente en la emergencia de un cambio en la configuración moral del orden social.

Ahora bien, algo que quisiera subrayar es que ese cambio no se produce de manera secuencial. Si lo intolerable supone la interpretación emotiva de una experiencia física, debemos considerar que el movimiento es un factor determinante del desarrollo de esa experiencia. Las sensaciones no anteceden al movimiento en el sentido de una expresión unidireccional, se dan al unísono y vuelven sobre sí mismas. El movimiento genera una experiencia interna que retroalimenta esa misma expresión externa. Aquí resulta clarificador el análisis de Mark Franko sobre el fenómeno de auto-afección de la danza de Isadora Duncan. Si bien el origen de la danza en Duncan se ubica en una percepción de la interioridad, la sucesión coreográfica produce una reacción del cuerpo al gesto precedente que va generando un movimiento circular internoexterno. Según Franko, "cuando la bailarina reintroyecta su propia danza como si incorporara un nuevo afecto, su danza se revela como auto-afectada: queda atrapada en la torsión giratoria de un retorno sobre sí misma" (2019b, p.45). En el devenir de la danza duncaniana se borran los límites entre el adentro y el afuera del cuerpo. Si concebimos la manifestación en el espacio público en los mismos términos, podemos entender que el estallido supuso una experiencia de auto-afectación, una vivencia colectiva de lo intolerable que desenvolvió un cuerpo empático con límites imprecisos. De este modo, la experiencia compartida de los cuerpos movilizados generó una consciencia política nueva articulada por un cambio en la percepción.

El concepto de movilización propuesto por el sociólogo y teórico de la danza Randy Martin afirma que, en el ámbito de la política, no existe separación entre un cuerpo actuante y una mente pensante. La movilización no surge de una mente que decide traducir sus ideas en acciones corporales, la política nace de cuerpos que ya están en movimiento. No hay división cartesiana. Lo político emerge en la movilización misma. Para Martin, las dinámicas de la movilización de los cuerpos en el espacio constituyen un factor del orden social implícito, inseparable de las dinámicas de lo político (Martin, 1998). Así, la movilización es "what moving bodies accomplish through movement [aquello que los cuerpos en movimiento consiguen a través del movimiento]" (Martín, 1998, p. 4). Es el resultado de un accionar colectivo inherente a la vida en sociedad.

Por otra parte, para Martin, la "producción" de la danza construye una determinada capacidad para el movimiento mientras que el "producto" de esta acción "is not the aesthetic effect of the dance but the materialized identity accomplished through the performativity of movement [no es el efecto estético de la danza sino la identidad materializada a través de la performatividad del movimiento]" (Martin, 1998, p.4). La danza es una disciplina que produce cuerpos, es decir, que hace que los sujetos encajen en un orden social determinado, pero por el otro lado, y de manera fundamental, representa "the reflexive mobilization of the body [la movilización reflexiva del cuerpo]” (Martin, 1998, p.6). Es una práctica que puede revelar al intérprete y al espectador "the very means through which bodies gather [los medios específicos a través de los cuales los cuerpos se reúnen]" (Martin, 1998, p.6). Martin subraya, en este sentido, la potencialidad política de la danza como una herramienta de movilización. Aquí el de pone en evidencia que la danza o el movimiento reflexivo no sólo se encuentran atravesados por lo colectivo, sino que son capaces de generarlo. Como apunta Gerald Siegmund en un artículo en el que analiza la obra de Martin, la movilización no designa exactamente el movimiento sino la capacidad para el movimiento, es una potencialidad en acción (Siegmund, 2016, p.28). A través de la movilización, los cuerpos atraviesan un terreno que, en el mismo acto, constituyen (Martin, 
1998, p.4). No obstante, la movilización al igual que lo intolerable designa un terreno de conflicto en el que colisionan fuerzas contrapuestas, un espacio abierto al acontecimiento.

\section{COREOPOLÍ́TICA Y DESIDENTIFICACIÓN}

En este sentido, podríamos afirmar que existe una dimensión coreográfica del poder. Hay dispositivos en el espacio público que determinan una movilización hegemónica. En un texto ampliamente citado en el campo de los estudios de danza, André Lepecki (2016) llama a esta dinámica coreopolicía por oposición a la coreopolitica, retomando la terminología propuesta por Jacques Rancière (1996) entre política y policía. Siguiendo a Lepecki, "el movimiento coreopoliciado puede ser entonces definido como cualquier movimiento incapaz de romper la interminable reproducción de una circulación de subjetividad consensual impuesta en donde ser es encajar en un patrón precoreografiado de circulación, corporealidad y pertenencia" (2016). La coreopolicía se relaciona con una subjetividad consensual, con la suscripción a un orden establecido.

Por oposición, la coreopolítica se asocia, según Lepecki, a la idea de libertad. Para él, a partir de su interpretación de la filosofía de Hannah Arendt, lo que hace falta para que no desaparezca la política en un mundo como el actual sumergido en la "sociedad de control" es la experiencia de la libertad. En este sentido afirma: "la desaparición de la cosa política del mundo es la desaparición de la experiencia y práctica del movimiento como libertad” (Lepecki, 2016). Por esta misma razón, la tarea (política) del bailarín para Lepecki "es imaginar y representar una política del movimiento como una coreopolítica de la libertad" (Lepecki, 2016).

Ahora bien, por más que retoma su terminología, Lepecki no da cuenta del sentido que los términos de política y policía tienen en la obra de Rancière, El desacuerdo (1996). Para Rancière la policía es primeramente un "orden de los cuerpos" (1996, p.44), sin embargo, el punto crucial está en el hecho de que se trata de un orden que determina lo visible y lo decible, no la libertad y la sujeción. En este sentido, "la policía no es tanto un disciplinamiento de los cuerpos como una regla de su aparecer" (Rancière, 1996, p.45). La policía es una regulación determinada del régimen de aparición de los cuerpos. Como contrapartida, "la política [...] hace ver lo que no tenía razón para ser visto, hace escuchar un discurso allí donde sólo el ruido tenía lugar" (Rancière, 1996, p.45). La política rompe una configuración de lo sensible a partir del principio de emergencia de la "parte de los sin parte", es decir, la aparición de un nuevo actor que logra articular una demanda que anteriormente no era ni siquiera concebida. La política no es un ejercicio de la libertad, es más bien una reconfiguración de la policía a partir de la aparición de un cuerpo que antes era imperceptible. Los cuerpos son libres en el dispositivo, porque el dispositivo incluye una operacionalización específica de la experiencia de libertad. El sujeto es libre en el dispositivo policíaco. La política no trata de apelar a un valor intrínseco a la esfera individual, sino de propiciar una nueva repartición de lo sensible. Si se quisiera designar un principio exterior que motoriza la política ese principio es el de la igualdad.

La política es en sí un asunto de "modos de subjetivación". Por esta razón, lo que caracteriza a la subjetivación política es su capacidad para generar una enunciación que no existía en la constitución policial de la comunidad (Rancière, 1996, p.52). En este sentido, según Rancière, el modo de subjetivación no crea sujetos políticos ex nibilo, los crea al transformar identidades definidas. La subjetivación política arranca a los sujetos de la naturalidad de su identidad, implica una toma de distancia con respecto a sí mismo. Por eso “toda subjetivación [política] es una desidentificación" (Rancière, 1996, p.53), porque supone una negación de la identidad policíaca. El "tomar la palabra” no es la expresión de un sí mismo, es justamente lo contrario, la desregulación de sí mismo. "Tomar la palabra” es asumir una subjetividad política que emerge en el mismo momento de la enunciación.

Ahora bien, lo que proponemos aquí, sobre la base de una consideración del orden social como movilización (Martin, 1998), es que ese momento de desidentificación inherente a la subjetivación política 
(Rancière, 1996) es un estadio imbricado con el movimiento en su triple condición coreográfica, kinestésica y empática (Foster, 2011). La desidentificación constituye una tarea fundamentalmente cinética y afectiva que implica un cambio en la percepción y en la economía moral (Fassin y Bourdelais, 2005) guiado por la movilización reflexiva del cuerpo de la que habla Randy Martin, pero también por un fenómeno de auto-afectación como el propuesto por Franko (2019a), es decir, por un fenómeno que proviene del mismo movimiento introyectado. Es desde ese lugar que la obra Recorte de Jorge Cárdenas cayendo teoriza coreográficamente la movilización política de diciembre del 2001. La "parte de los sin parte", es decir, el nuevo sujeto político que se hizo presente en ese estallido social supuso una instancia cinética de desidentificación: un acontecimiento coreopolítico.

\section{LA HISTORICIDAD DE LOS CUERPOS EN PUGNA}

¿Qué es moverse políticamente en una obra escénica? Una compañera me contó una vez su sensación de perplejidad durante un seminario universitario sobre danza y política en el que se le pidió que se "mueva políticamente”. Desde cierto punto de vista, se puede pensar en ese ejercicio práctico como un disparador para una clase, una manera de proponer a los alumnos que lleven al cuerpo su reflexión previa sobre la temática. Sin embargo, la pregunta también nos lleva a pensar en diferentes facetas de la cuestión: ¿hay una estética universal para danzar la política? ¿Es posible moverse políticamente en el contexto de un seminario universitario? ¿La política se encuentra en la forma del movimiento? ¿Si no se encuentra en la forma, en dónde está? La primera respuesta que quisiera proponer es que la politicidad de una obra de danza o performance no está en la forma de modo abstracto, sino en el modo en que la forma interviene en el mundo. De ese modo, la politicidad de la danza resulta indisociable de una cultura, de una sociedad y de una historia determinadas. Cuando imaginamos un gesto del cuerpo que representa lo político estamos repitiendo fórmulas metafóricas históricamente constituidas.

Moverse políticamente no es otra cosa que dialogar corporalmente con un clisé, entendiendo al clisé no como una estética insulsa o degradada sino como un gesto al que se le ha asignado históricamente una determinada significación de la que le resulta muy difícil separarse. Por ejemplo, la danza de masas de principios del siglo XX, estudiada por Mark Franko (2002) representaba formas de movimiento que dialogaban con los gestos de la protesta obrera: poses desafiantes de los cuerpos con los puños en alto, actitudes de disponibilidad para la acción, un torso ligeramente adelantado con las piernas desplegadas, rostros desencajados. Eran fórmulas del pathos históricamente constituidas. Lo que nos indica esto es que la carga política de los gestos supone una historiografía, a veces implícita, de los símbolos que enuncian. La política entra en contacto con la coreografía a partir de una relación diacrónica que la comunica con tradiciones expresivas y representacionales propias del campo, y sincrónica, que hace posible el diálogo entre el gesto escénico y los que se manifiestan en la sociedad en un momento histórico preciso. La danza puede hacer referencia a una lucha política presente en el espacio público a través de gestos que funcionan como citas, citas coreográficas. De este modo, queda claro que es la carga histórica y social el elemento determinante para la politicidad del gesto.

En igual medida, podría decirse que la memoria de las luchas pasadas emerge en la acción misma. No nos movemos políticamente desde el vacío, dialogamos con un pasado, con una tradición de enfrentamientos. Es esa presencia inherente a la acción política la que es relatada por la obra Instrumento para estrellar de Diana Szeinblum ${ }^{3}$. La obra le fue encomendada en 2017 por el Centro Cultural Kirchner como parte del ciclo de perfomances En el nombre del nombre, dentro de la muestra Les visitants curada por Mariana Obersztern y se estrenó en abril de 2018. El contexto del trabajo de ensayo fueron las masivas movilizaciones contra la reforma laboral y previsional de diciembre de 2017 y la feroz represión del gobierno macrista. En una charla que mantuve con Diana en ese momento, me dijo que las imágenes de esas manifestaciones la habían conmovido a un punto tal que no podía tratar un tema en su obra que fuera ese. La sinopsis del trabajo dice: 
Entendemos que un cuerpo en una manifestación es el soporte de una ideología. Ese cuerpo vibrante, amalgamado con otros en esa escena, es traspasado y modificado por fuerzas: históricas, simbólicas, represivas, entre otras. La acción es observar las fuerzas que intervienen. La operación performática será vaciar la escena real, despojarla: quitar a las personas del entorno, el contexto, los elementos, quedarse con el hueso: el gesto puro. Entonces aparece el vacío. Se devela así un instante capaz de irradiar una abismal carga emotiva. Ese momento visibiliza la tensión social como una energía contenida en una caja de resonancia. ¿Será posible que la presencia y el movimiento de un cuerpo en escena puedan revelar maneras novedosas de concebir lo político?

La obra se basó en una investigación fotográfica acerca de la gestualidad que emerge de las movilizaciones sociales tomando como fuente el registro de manifestaciones ocurridas en diferentes ciudades de Latinoamérica durante los últimos años. Se relevaron y seleccionaron fotos y videos de manifestaciones en Buenos Aires, San Pablo, Ciudad de Guatemala y México DF en las que se exhibían actos de represión, gestos de desafío o abatimiento.

La obra comenzaba con una escena grupal en la que cada uno de los intérpretes reproducía un gesto particular correspondiente a alguno de los archivos visuales sobre movilizaciones que habían sido abordados por el trabajo. Esa primera imagen funcionaba como una presentación de la temática de la obra, una suerte de tableau vivant. Luego de ese momento las escenas se desarrollaban a partir de un procedimiento específico que consistía en reproducir las imágenes fotográficas de las movilizaciones, que en muchos casos plasmaban actos de represión en los que se observaban a agentes de las fuerzas de seguridad y manifestantes enfrentados. Los bailarines interpretaban alguno de los personajes siguiendo una función coreográfica específica y reproduciendo la tensión de fuerzas que componían la escena, su tenacidad, su resistencia, su pesadez. Luego, se retiraban uno a uno, dejando aislado al personaje central, generalmente un sujeto violentado, que conservaba en su cuerpo la forma que le había impreso esa tensión. La cantidad de intérpretes involucrada variaba según la imagen que se estaba recreando. En el pasaje que iba de la situación de disputa entre diversos intérpretes a la sustracción del actor principal, se producía la transformación de una tensión externa en interna, lo que a su vez implicaba un cambio de apoyos del cuerpo en cuestión. La memoria corporal de la resistencia a una fuerza externa se volvía representación de una potencia internalizada. El cuerpo abstraído de una escena cuyos restos de tensión continuaban estando presentes funcionaba como un cuerpo literalista (Franko, 2019b, pp.172-173), una caja de resonancia en la que se proyectaban diferentes ideas y afectos. Finalmente, en el desenlace de la obra la metodología cambiaba. La escena no consistía en la representación de una de las fotos del archivo, sino en una acción realizada por todos los intérpretes de la obra: se reunían en el centro de la escena y comenzaban a saltar juntos emulando a pequeña escala la energía que desprende una manifestación.

Diana Szeinblum ${ }^{4}$ afirma que el trabajo de esta obra consiste en escenificar fuerzas opuestas, cuerpos que son modificados por otros cuerpos, y que al ser quitada de la escena la fuerza opresora se genera un efecto de sustracción. Así, el cuerpo que queda es un cuerpo que empieza a emanar significados, se transforma en un resonante del pasado, del presente de los conflictos sociales, encarna una potencia. El cuerpo deviene un médium que revive una imagen del pasado, pero aportando su propia experiencia de vida. El intérprete le entrega al médium su propia existencia histórica. Se genera un mecanismo a partir del cual un archivo sociohistórico cobra vida, construyendo una escena que no sólo se ofrece a la contemplación, sino que también mira al espectador. Para Diana, el procedimiento hace que ciertos espectadores puedan volver a revivir una experiencia física de participación política guardada en su memoria corporal y afectiva. Podríamos inferir que el pasaje del cuerpo en tensión con otros al cuerpo solo, sustraído, implica el pasaje de un acto de resistencia (reactiva) a la afirmación de una potencia (activa). Hay una fuerza negativa que se transforma en positiva, adquiriendo la forma de un acto declamatorio. Diana sostiene, en este sentido, que de la quietud de ese cuerpo emana una fuerza que se proyecta al avenir. La acción escénica sintetiza, de algún modo, la dimensión de historicidad que caracteriza a las luchas político artísticas (Vallejos, 2021). 
Podría decirse que el dispositivo de sustracción que define el nudo central del trabajo propone casi un proceso de refinamiento modernista de la acción, como si se buscara llegar, - para el caso de las coreografías de la protesta -, al "gesto puro" característico de la estética de la indiferencia de la danza posmoderna norteamericana, al menos según la lectura clásica de Sally Banes (1987). Sin embargo, en el marco de una representación de la lucha política, lo que emerge, en términos de Rancière (1996), es un cuerpo desidentificado que expresa la reinvención de sí: el nudo coreográfico, pero también kinestésico y empático del acto de rebelión. Se retiran los personajes históricos para conservar el gesto ficcional transhistórico del cuerpo que resiste. Ese momento visibiliza la tensión social como una energía contenida en una caja de resonancia. Se trata de acceder, en cierto sentido, a la politicidad de aquello que Laurence Louppe (1997) denomina "fuerza", por oposición a la idea de "signo". Fuerza entendida como una suerte de trabajo interno anterior a la emergencia del gesto. Para Louppe es la danza contemporánea la que otorga a esa fuerza oprimida por el dispositivo disciplinario foucaultiano un canal de acceso al universo simbólico (Louppe, 1997, p.48). El cuerpo arrancado a la situación de violencia conserva los restos de una lucha y se transforma en un signo que asume la ausencia, pero a la vez potencia la visibilidad de aquello que permanece. Como afirma Diana Taylor (1997, p.27), a veces el trabajo artístico se reduce simplemente a hacer ver algo evidente que por razones ideológicas no podemos observar. El mensaje político antimetafórico es quizás la simple presencia de esos cuerpos, la posibilidad de que continúen estando presentes aquí y ahora.

\section{LA INGOBERNABILIDAD COMO LEGADO}

Una de las referencias con las que trabajó Diana fue el proyecto Ausencias del fotógrafo argentino Gustavo Germano. Una obra en homenaje a las víctimas de la dictadura militar en Argentina y Brasil, en la que se reconstruyeron fotografías de los álbumes de 25 familias, tomando nuevas fotos exactamente en los mismos lugares en los que habían sido tomadas anteriormente. En esa obra, la imagen reconstruida devela la ausencia del desaparecido y el duelo de quien permanece. La obra de Diana funciona como un espejo de ese proyecto, no se trata de evidenciar la carga de una ausencia, sino de sopesar la historicidad de una presencia. Es en las luchas de los pueblos que los desaparecidos aparecen. La obra complementa desde un enfoque coreográfico una política de la memoria y de la potencialidad subversiva, afirmando una presencia ineludible. Una fuerza que continúa presente, que no desaparece. Performear la política es retomar un conflicto en su devenir. Es intervenir en la diacronía que construye el sentido estético y político de un gesto específico.

El coreógrafo Marten Spanberg (2017) opone el trabajo de la coreografía con el de la arquitectura: si la arquitectura construye un espacio que deviene tiempo, la coreografía articula un tiempo que deviene espacio. Del mismo modo, podemos inferir que el acontecimiento de la movilización como coreografía construye un nuevo espacio para lo político. Ese espacio no se reduce a lo cinético, sino que implica una dimensión propioceptiva y empática, además de simbólica. Se trata de un espacio que contiene y exhibe una fuerza potencialmente ingobernable. Isabell Lorey (2015) afirma que la precariedad es un elemento constitutivo de las sociedades capitalistas actuales, gobernar en este contexto implica la capacidad de negociar cuál es el nivel de precariedad que una sociedad puede soportar sin devenir ingobernable. El 2001 constituyó un momento histórico en el que la precariedad neoliberal encontró su límite, generando un espacio de ingobernabilidad. En definitiva, lo que la obra de Diana Szeinblum, Instrumento para estrellar, presenta es una coreografía que construye ese espacio de ingobernabilidad, una ingobernabilidad que se proyecta históricamente como "legado". El tiempo de la política institucional, luego del 2001, fue el de construir un nuevo orden social, un nuevo gobierno, en cierto sentido, más justo que los de gobiernos anteriores, pero la danza nos recuerda que la memoria afectiva del evento ingobernable permanece en la memoria de los pueblos como una amenaza latente, como una caución firmada por la historia. 


\section{REFERENCIAS}

Banes, S. (1987). Terpsichore in Sneakers. Middletown: Wesleyan University Press.

Fassin, D. y Bourdelais, P. (Eds.). (2005). Les constructions de l'intolérable. Paris: La Découverte.

Foster, S. L. (2011). Choreographing empathy: Kinesthesia in Performance. Abingdon: Routledge.

Foster, S. L. (2016). Coreografías de la protesta. En V. Pérez Royo y D. Agulló (Eds.), Componer el plural (pp. 71-106). Barcelona: Mercat de les Flors.

Franko, M. (2002). The work of dance: Labor, movement, and identity in the 1930s. Middletown: Wesleyan University Press.

Franko, M. (2019a). Choreographing Discourses: A Mark Franko Reader. Abingdon: Routledge.

Franko, M. (2019b). Danzar el modernismo/Actuar la politica. Buenos Aires: Miño y Dávila.

Lepecki, A. (2016). Coreopolicía y coreopolítica o la tarea del bailarín. Nexos: Cultura y vida cotidiana. Recuperado de: https://cultura.nexos.com.mx/?p=10775

Louppe, L. (1997). Poétique de la danse contemporaine. Bruxelles: Contredanse.

Lorey, I. (2015). State of Insecurity: Government of the Precarious. London: Verso.

Marin, L. (2009). Poder, representación, imagen. Prismas. Revista de historia intelectual, 13(2), 135-153.

Martin, R. (1998). Critical Moves: Dance Studies in Theory and Politics. Durham: Duke University Press.

Rancière, J. (1996). El desacuerdo: Política y fllosofía. Buenos Aires: Nueva Visión.

Siegmund, G. (2016). Mobilization, Force, and the Politics of Transformation. Dance Research Journal, 48(3), 27-32.

Spanberg, M. (2017). "Post-dance, An Advocacy”. En Andersson, D.; Edvarsdsen, M. y Spanberg, M., Post-Dance. Estocolmo: MDT.

Sztulwark, D. (2019). La ofensiva sensible. Neoliberalismo, populismo y el reverso delo político. Buenos Aires: Caja Negra.

Taylor, D. (1997). Disappearing Acts: Spectacles of Gender and Nationalism in Argentina's "Dirty War". Durham y Londres: Duke University Press.

Vallejos, J. I. (2021). Historicidad, sincroni\# a y activismo de lo sensible: el Congreso Escena Poli\#tica en Buenos Aires. Aisthesis, Revista chilena de investigaciones estéticas, 69, (en prensa).

\section{Notas}

1 Comentario realizado por Juan Pablo Gómez en la Charla abierta: «El cuerpo-danza en la crisis del 2001» realizada el 4 de diciembre de 2019, en el IIGG de la UBA.

2 Entrevista de Florencia Montaldo con el autor en el mes de abril de 2021.

3 En el siguiente link puede observarse una pieza de 15 minutos realizada para el ciclo de pensamiento sobre Democracia del Proyecto Ballena del CCK (Centro Cultural Kirchner) que reproduce escenas de la obra Diana Szeinblum (2021) INSTRUMENTO para ESTRELLAR con subtítulos. Youtube. https://www.youtube.com/watch?v=qzvM3IyzkDA

4 Entrevista de Diana Szeinblum con el autor en el mes de junio de 2021. 